\title{
The appropriate use of fecal immunochemical testing
}

\author{
Nauzer Forbes MD MSc, Robert J. Hilsden MD PhD, Steven J. Heitman MD MSc
}

Cite as: CMAJ 2020 January 20;192:E68. doi: 10.1503/cmaj.190901

See related article at www.cmaj.ca/lookup/doi/10.1503/cmaj.191566

1

Fecal immunochemical testing should be performed every 1-2 years, ideally as part of a colorectal cancer screening program ${ }^{1,2}$

Fecal immunochemical testing, a stool immunochemical test for occult blood, is the recommended primary colorectal cancer screening modality in Canada for average-risk individuals, defined as those aged $50-75$ years without a personal or first-degree family history of colorectal cancer or advanced polyps before age 60 . Fecal immunochemical testing is recommended over other modalities owing to established benefit and cost-effectiveness. ${ }^{1}$

2

Fecal immunochemical testing has higher positive predictive value for colorectal cancer and advanced polyps than guaiacbased fecal occult blood testing

Depending on cut-offs used, up to $54 \%$ of patients with a positive fecal immunochemical test will have 1 or more advanced polyp(s), and up to $8 \%$ will have colorectal cancer. ${ }^{2}$ The sensitivity of a single fecal immunochemical test is up to $79 \%$ (95\% confidence interval $[\mathrm{CI}] 69 \%-86 \%)^{3}$ for colorectal cancer and $40 \%(95 \% \mathrm{Cl} 33 \%-47 \%)$ for advanced polyps. ${ }^{4}$

A single positive fecal immunochemical test should prompt referral for colonoscopy, which should ideally be performed within 8 weeks In a given testing cycle, a single fecal immunochemical test (positive or negative) is adequate. Multiple samples are wasteful, and can potentially delay referral while the patient performs unnecessary additional tests. ${ }^{3}$

Fecal occult blood testing or fecal immunochemical testing are not intended for use in symptomatic patients, including those with suspected gastrointestinal bleeding ${ }^{5}$

A negative fecal immunochemical test should not be reassuring in symptomatic patients, who should be referred to specialists for consideration of endoscopy and other investigations.

After colonoscopy, endoscopists should provide recommendations for when to resume screening, by either fecal immunochemical testing or repeat colonoscopy; fecal immunochemical testing should not be performed before these recommended times

Early rescreening with fecal immunochemical testing after colonoscopy is discouraged, because of low yield and unjustifiable cost. However, if for any reason a fecal immunochemical test has been repeated on a patient between intervals and is positive, a referral for colonoscopy should be made. ${ }^{2}$

\section{References}

1. Canadian Task Force on Preventive Health Care. Recommendations on screening for colorectal cancer in primary care. CMAJ 2016;188:340-8.

2. Robertson DJ, Lee JK, Boland CR, et al. Recommendations on fecal immunochemical testing to screen for colorectal neoplasia: a consensus statement by the US Multi-Society Task Force on Colorectal Cancer. Gastroenterology 2017; 152:1217-37.e3.

3. Lee JK, Liles EG, Bent S, et al. Accuracy of fecal immunochemical tests for colorectal cancer: systematic review and meta-analysis. Ann Intern Med 2014;160:171.

4. Imperiale TF, Gruber RN, Stump TE, et al. Performance characteristics of fecal immunochemical tests for colorectal cancer and advanced adenomatous polyps: a systematic review and meta-analysis. Ann Intern Med 2019;170:319-29.

5. Narula N, Ulic D, Al-Dabbagh R, et al. Fecal occult blood testing as a diagnostic test in symptomatic patients is not useful: a retrospective chart review. Can J Gastroenterol Hepatol 2014;28:421-6.

Competing interests: None declared.

This article has been peer reviewed.

Affiliations: Department of Medicine, Division of Gastroenterology and Hepatology; Department of Community Health Sciences, University of Calgary; Forzani \& MacPhail Colon Cancer Screening Centre, Calgary, Alta.

Correspondence to: Nauzer Forbes, nauzer.forbes@ucalgary.ca

CMAJ invites submissions to "Five things to know about ..." Submit manuscripts online at http://mc.manuscriptcentral.com/cmaj 